\title{
Determining the Critical Depth of Excavation and Investigating the Effect of Fault on the Resistance of Tehran Alluvial
}

\author{
Omid Asadzadeh Saghavaz, Manouchehr Ghorashi, Mohsen Pourkermani \\ Islamic Azad University North Tehran Branch, Tehran, Iran \\ Email: Omid.asadzadeh68@gmail.com,GHORASHI_manouchehr@yahoo.com,Pourkermani@gmail.com
}

How to cite this paper: Saghavaz, O.A., Ghorashi, M. and Pourkermani, M. (2018) Determining the Critical Depth of Excavation and Investigating the Effect of Fault on the Resistance of Tehran Alluvial. Open Journal of Geology, 8, 1027-1041. https://doi.org/10.4236/ojg.2018.810062

Received: June 16, 2017

Accepted: June 23, 2017

Published: September 30, 2018

Copyright $\odot 2018$ by authors and Scientific Research Publishing Inc. This work is licensed under the Creative Commons Attribution International License (CC BY 4.0).

http://creativecommons.org/licenses/by/4.0/

\begin{abstract}
In this paper, the effect of the burden of neighboring buildings on the stability of holes in a part of coarse-grained alluvial deposits of northern Tehran has been investigated. For this purpose two numerical and partial equilibrium methods have been used with FLAC and SLIDE software. As, the holes in the study area to the depth of $20 \mathrm{~m}$ in the without load state of the neighboring building and the building load of the 5-floor building in a distance of 3 meters from the depth edge were analyzed, and the results were compared and finally using the SLIDE software the guardian structure for deep recessed excavations was suggested which with this proposed guardian structure a high reliability coefficient of 1.5 can be achieved.
\end{abstract}

\section{Keywords}

Stability of Depth, Numerical Method, Partial Equilibrium Method, SLIDE, FLAC

\section{Introduction}

Due to the development of construction in the city of Tehran and the necessity of excavation, the development of geological classification for engineering purposes and in particular excavation seems necessary. For this purpose, in the present research, a part of the northwest alluvial deposits of Tehran is investigated in terms of engineering geology, and according to the alluvial the best method of excavation is suggested.

In this study sustainability analysis methods (numerical method and partial equilibrium) have been used. Also holes stability analysis has been done with numerical and partial equilibrium method for each section in different states in- 
cluding: Vertical and no-load mode along edge of the depth with numerical method using FLAC software, Vertical and 5-story building load mode of the depth at a distance of 3 meters from the edge of the depth with numerical method using FLAC software, Vertical and unloaded mode along the edge of the depth by partial equilibrium method using the Slide software and Vertical holes and 5-story building load mode of the depth at a distance of 3 meters from the edge of the depth by partial equilibrium method using the Slide software.

\section{Geology of the Study Area}

The study area is generally composed of Quaternary alluvial units due to many faults and high buildings. These deposits are divided into different units according to the study which include: Alluvial Formation of Hezardareh (Alluvial A of the Age of Pliocene), Heterogeneous Alluvial Formation in North of Tehran (Alluvial Bn) and Kahrizak clay silt (Alluvial Bs) (Indices $\mathrm{n}$ and $\mathrm{s}$ refer to the north and south) (Quaternary Pleistocene), Alluvial Formation of Tehran (Alluvial C to Quaternary Pleistocene) and current Alluvial (Alluvial D in the Holocene Quaternary period). Accordingly, the type of alluvial deposits of the study area according to the studies carried out by cheshmi et al. and based on the soil characteristics of the site of the depths and Objective observations of the studied depths (Amir Kabir and Niavaran) have been identified as Type C Alluvial species [1] (Figure 1).

\section{Methods}

In general, the available methods for sustainability analysis can be divided into two groups of numerical methods and partial equilibrium method [2].

\subsection{Sustainability Analysis with FLAC Software}

This software (FLAC), which is suitable for modeling large deformations, has the ability to model the behavior of soil, stone or other materials that may be found the pasty flow when they reach to the Limit surrender.

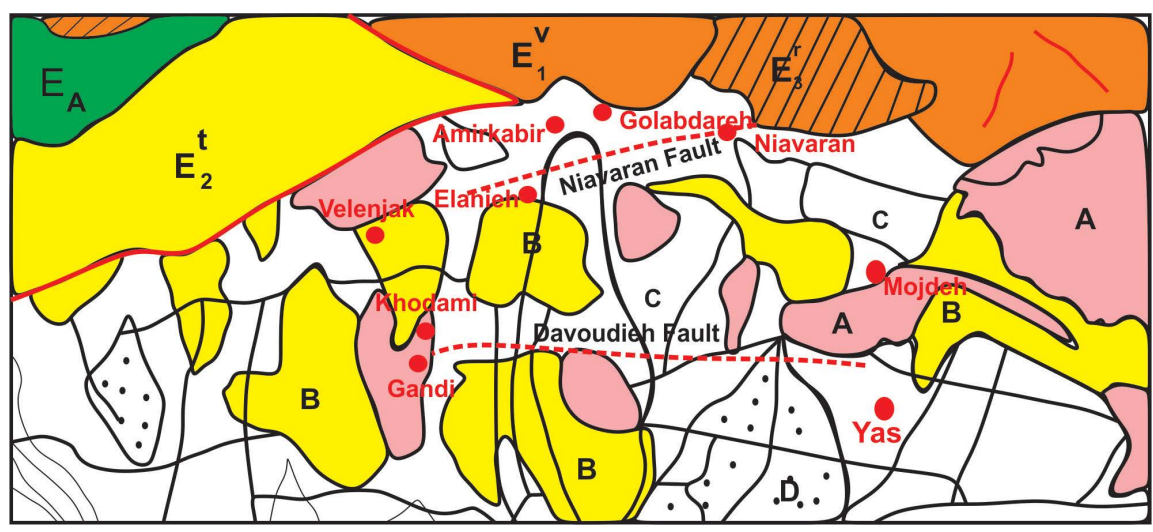

Figure 1. The sections studied in the box on Tehran Geological Survey 1:130,000. 
The SLIDE software is used to study the geomechanical characteristics, the geometry of the unstable region and the groundwater level and by highly detailed mathematical analysis provides a complete report of soil and rock mechanics and their effects in sustained conditions.

\subsection{Holes Stability Analysis and Propose a Maintenance Method}

In these analyzes the load of the lateral structure varies depending on the type of skeleton and how it is executed and how the calculations are based on engineering principles. For each floor one kilo Newton $/ \mathrm{m}^{2}$ of load is considered to be below ground that in analyzes the 5-floor building load is considered at a distance of 3 meters from the edge of the depth. The method of this study was to first analyze the hole in the normal way regardless of the neighboring building load to a depth of 20 meters in numerical and partial equilibrium using FLAC and SLIDE software, as first the depth of the hole was $1 \mathrm{~m}$ and the corresponding reliability coefficient was calculated and then in each step up to $20 \mathrm{~m}$ deep depth of the hole increased by $1 \mathrm{~m}$ and the confidence coefficients were calculated and recorded.

In Figure 2 and Figure 3 an example of the outputs of the FLAC and SLIDE software for the Amir Kabir hole at depths of 17 and 9 meters is shown respectively. As it can be seen based on the output of FLAC software in the case of a depth of 17 meters the confidence coefficient is 0.27 and according to the output of SLIDE software when the depth is 9 meters the coefficient of confidence is 0.45 .

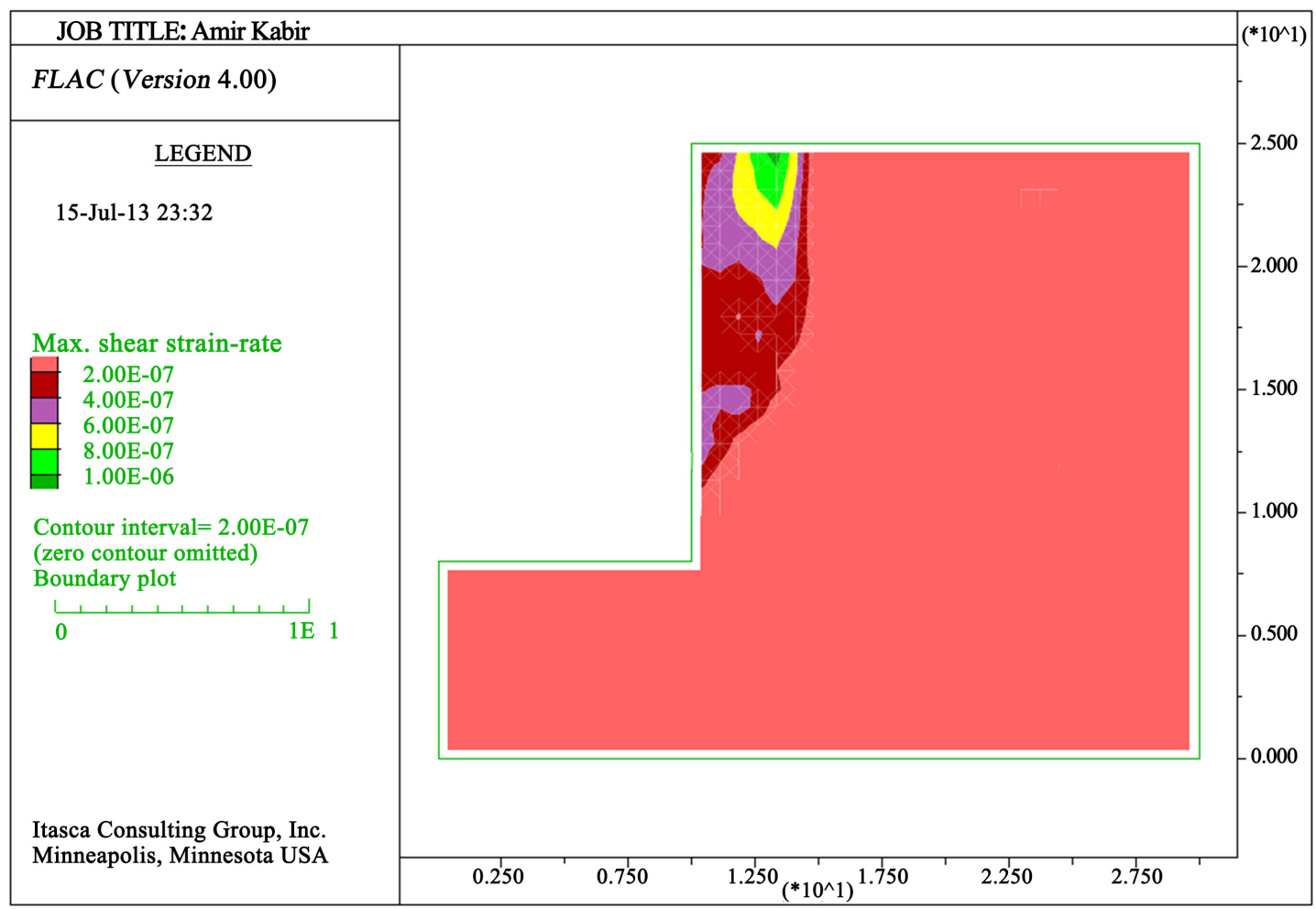

Figure 2. Analysis with FLAC software in the without load states at depths of 17 meters (Amir Kabir hole). 


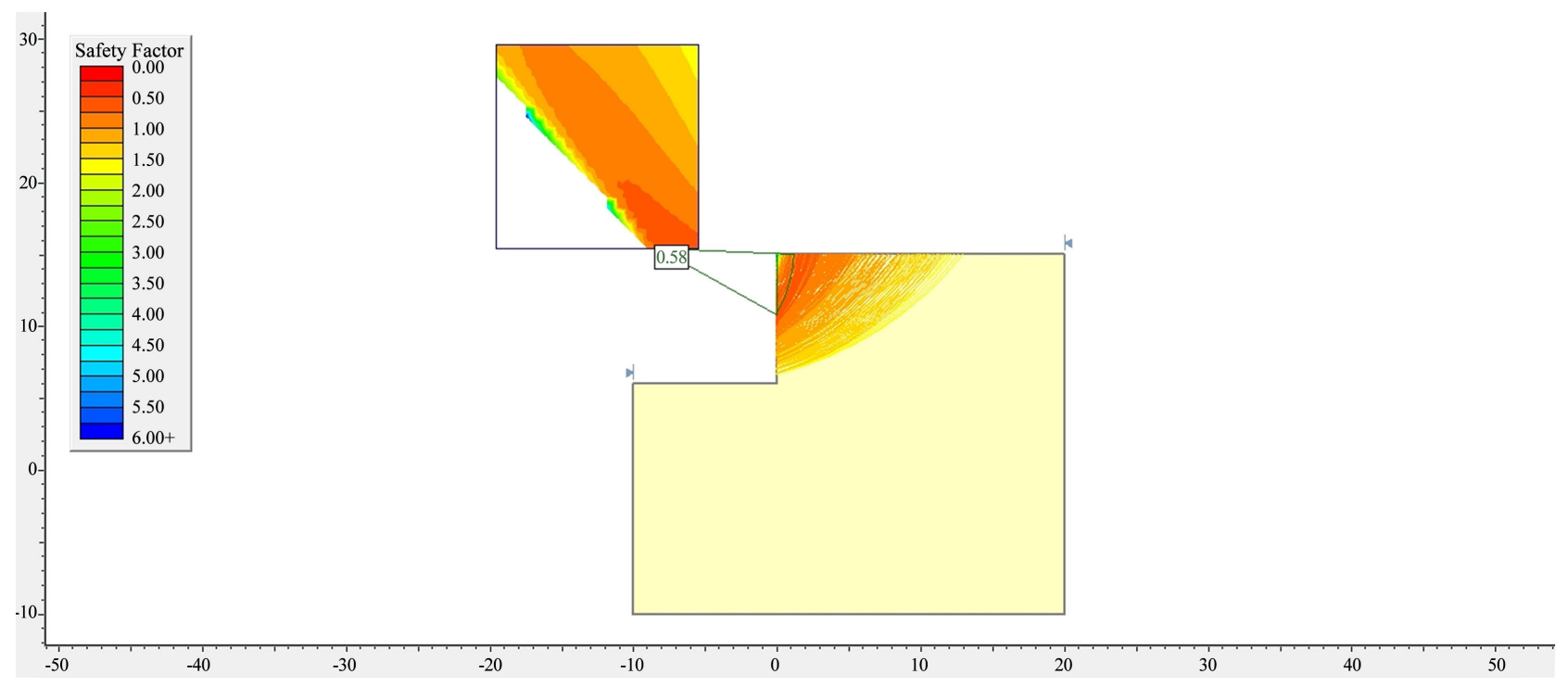

Figure 3. Analysis with SLIDE software in the without load states at depths of 9 meters (Amir Kabir hole).

After analyzes a 5-story building load has been calculated in normal operation and this time it is placed at a distance of 3 meters from the edge of the hole. The effect of it on hole stability has been investigated in two numerical and partial equilibrium methods and the corresponding results have been recorded. In Figure 4 a sample of analyzes performed by the FLAC software is shown for a situation in which the load of a neighboring building is at a distance of 3 meters from the edge of the hole and a depth of the hole is 5 meters.

In Figure 5 a sample of analyzes performed by the SLIDE software is shown for the case where the load is located at a distance of 3 meters from the edge of the hole and the depth of the hole is $14 \mathrm{~m}$.

The results of the analyzes performed for Amir Kabir hole in normal mode and the existence of the neighboring building load are shown in Table 1 that the red values represent the critical depth of the excavation, their diagrams in the form of the changes in the reliability coefficient versus depth of excavation for each numerical method and partial equilibrium are shown in Figure 6 as the depth of excavation increases the Confidence coefficients follows a downward trend.

The minimum Confidence coefficients considered for stability in most projects for slopes and recesses is 1.5 [3].

In Figure 7 and Figure 8 a sample of FLAC and SLIDE software outputs for the Niavaran hole at depths of 5 and 15 meters is shown respectively. As it can be seen based on the output of the FLAC software in the case of a depth of 5 meters the confidence coefficient is 1.04 and based on the output of SLIDE software when the depth is 8 meters the confidence coefficient is 0.95 .

After performing analyzes in normal mode the load of a 5-story building was calculated and this time within a distance of 3 meters from the edge of the hole its effect on the stability of the hole is investigated by numerical and partial equi- 
librium and the corresponding results are recorded. In Figure 9 a sample of analyzes performed by the FLAC software is shown for the case where the load of the neighboring building is located at a distance of 3 meters from the edge of the hole and the depth of the hole is 10 meters.

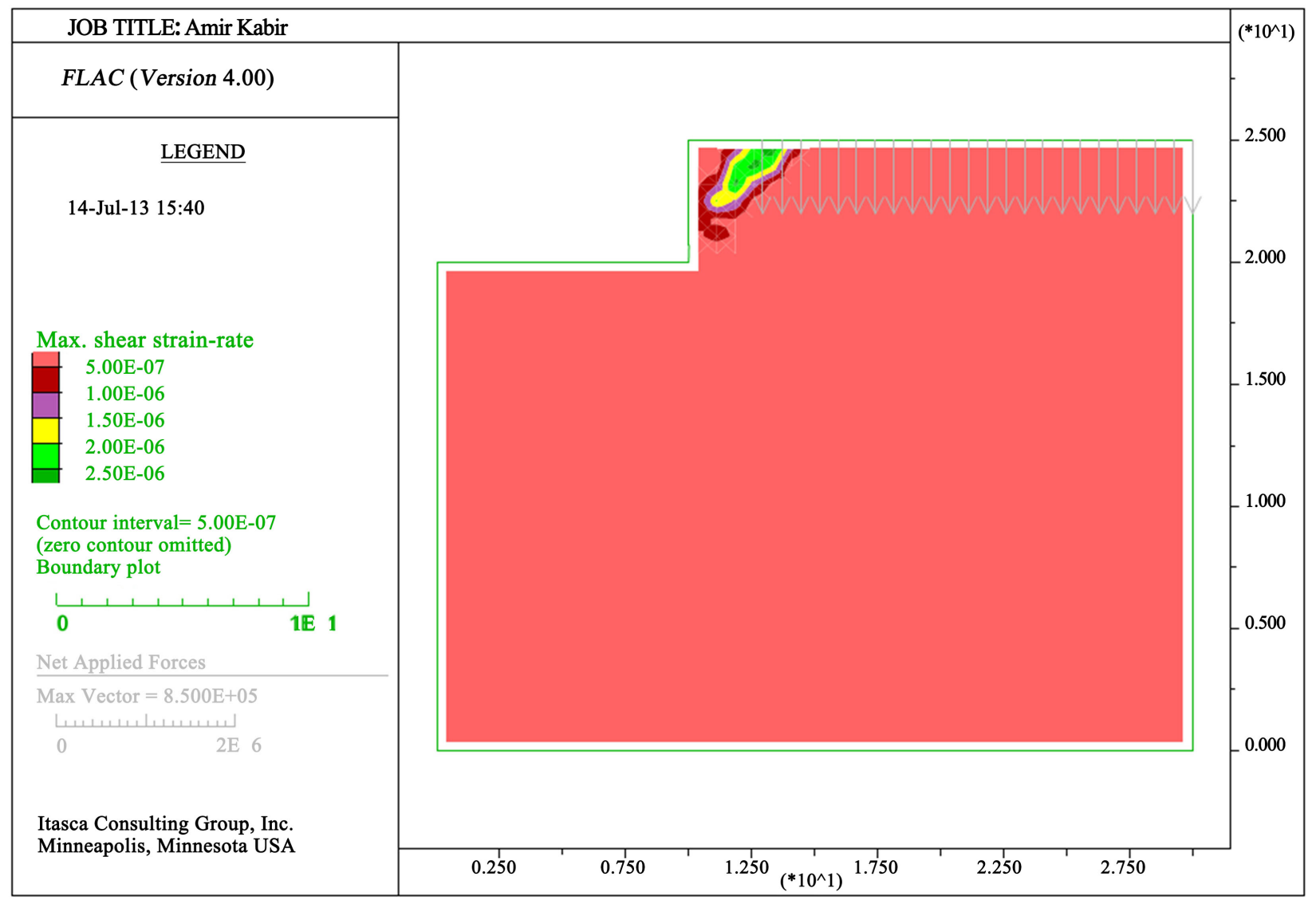

Figure 4. Analysis with FLAC software in the with load states at depths of 5 meters (Amir Kabir hole).

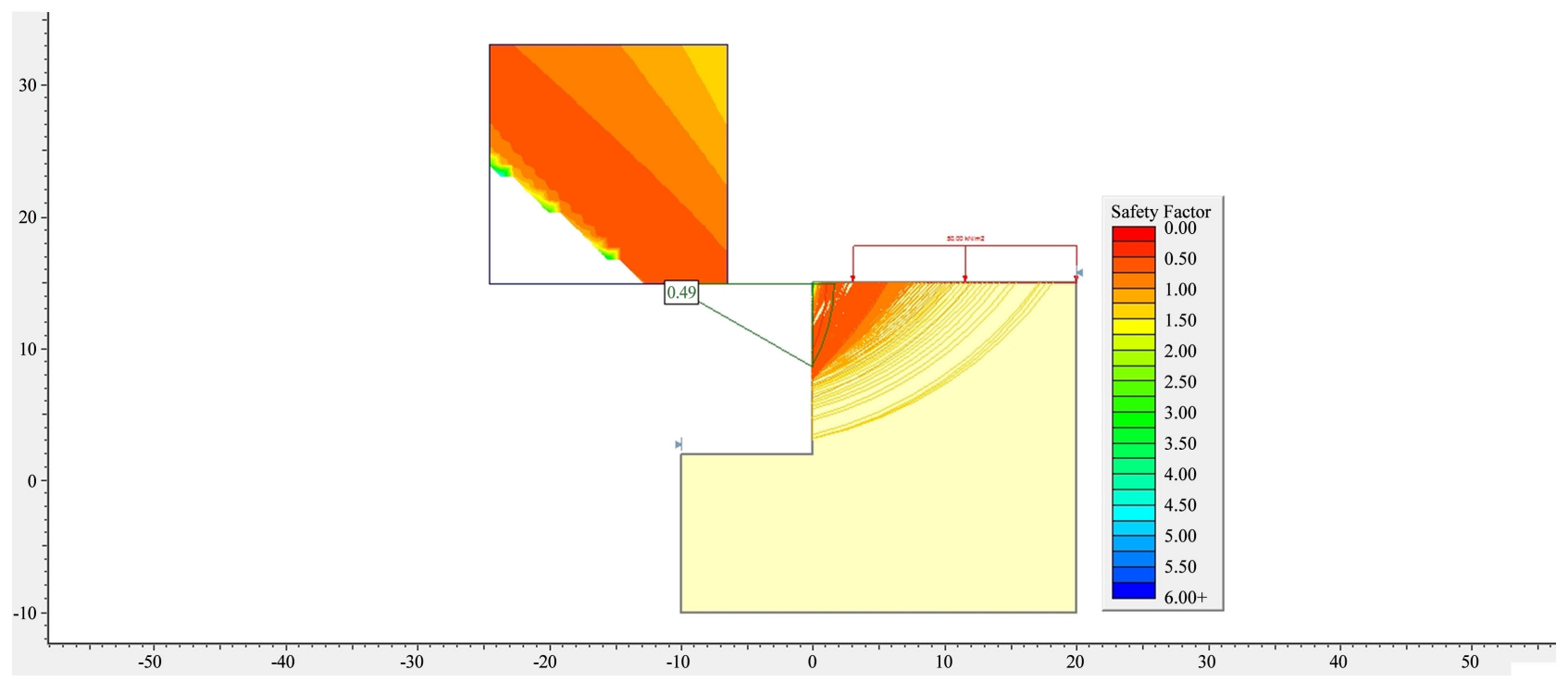

Figure 5. Analysis with SLIDE software in the with load states at depths of 14 meters (Amir Kabir hole). 


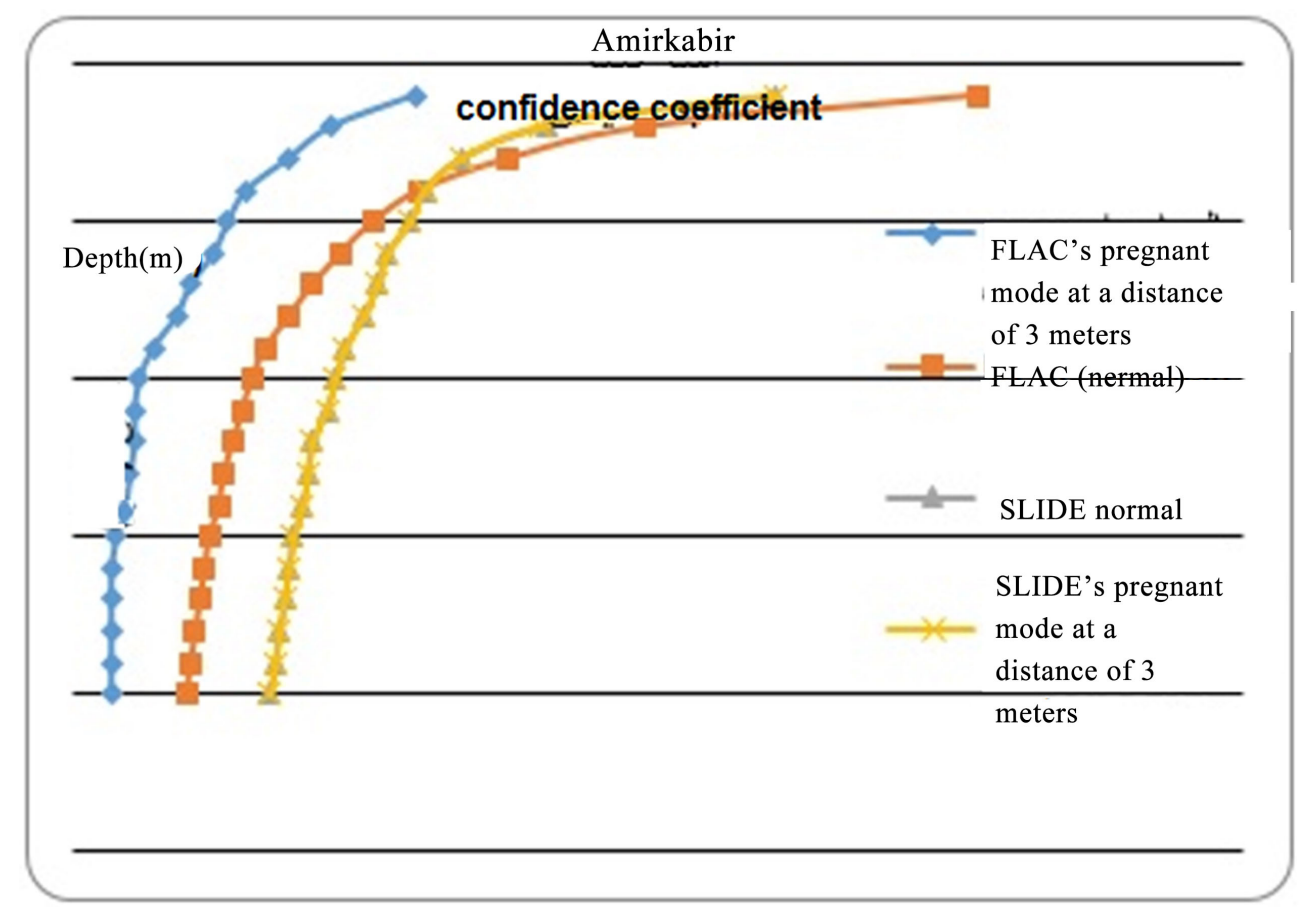

Figure 6. Depth-confidence change for both SLIDE and FLAC software for normal and pregnant mode (Amirkair hole).

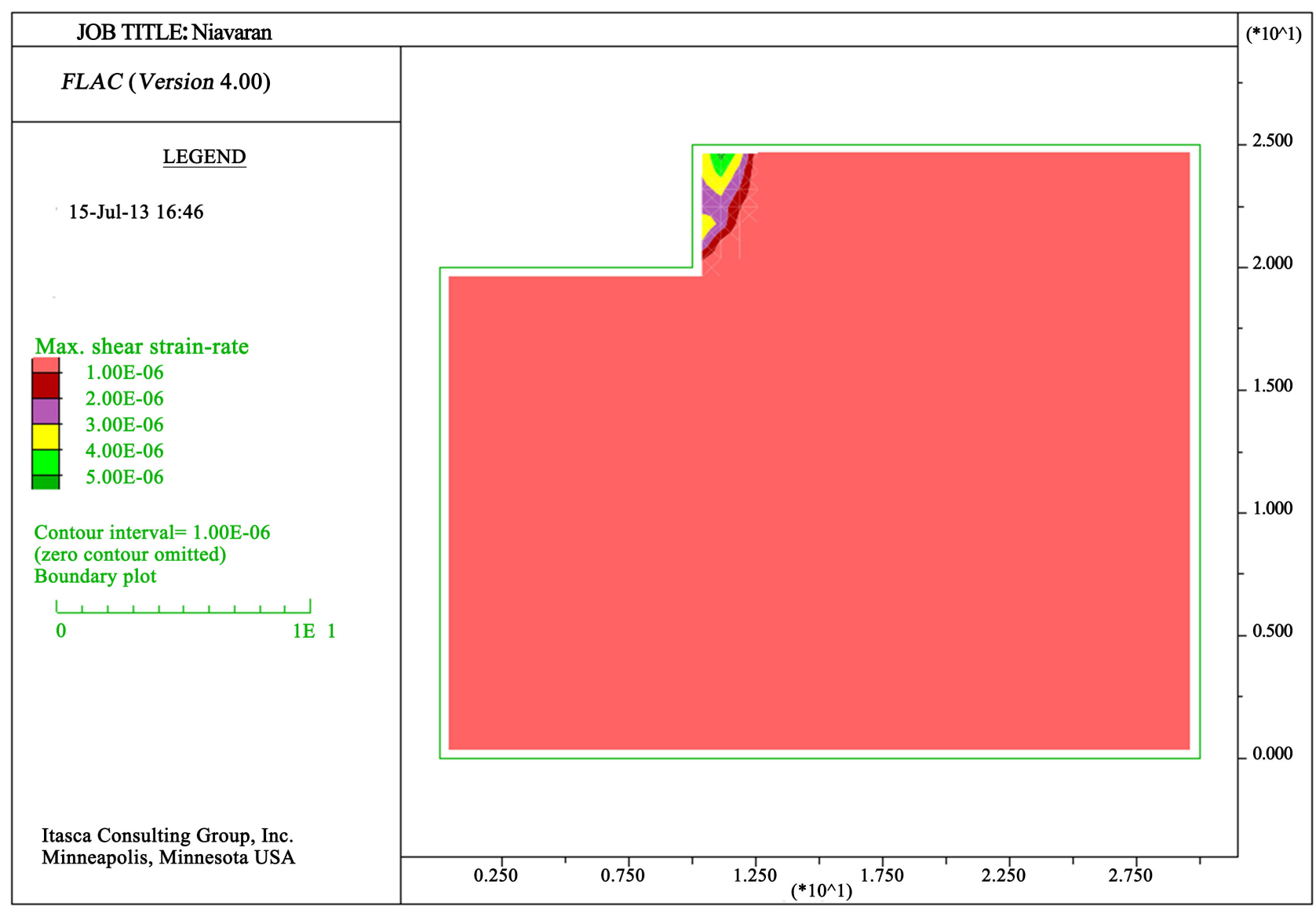

Figure 7. Analysis with FLAC software in the normal states at depth of 5 meters (Niavaran hole). 


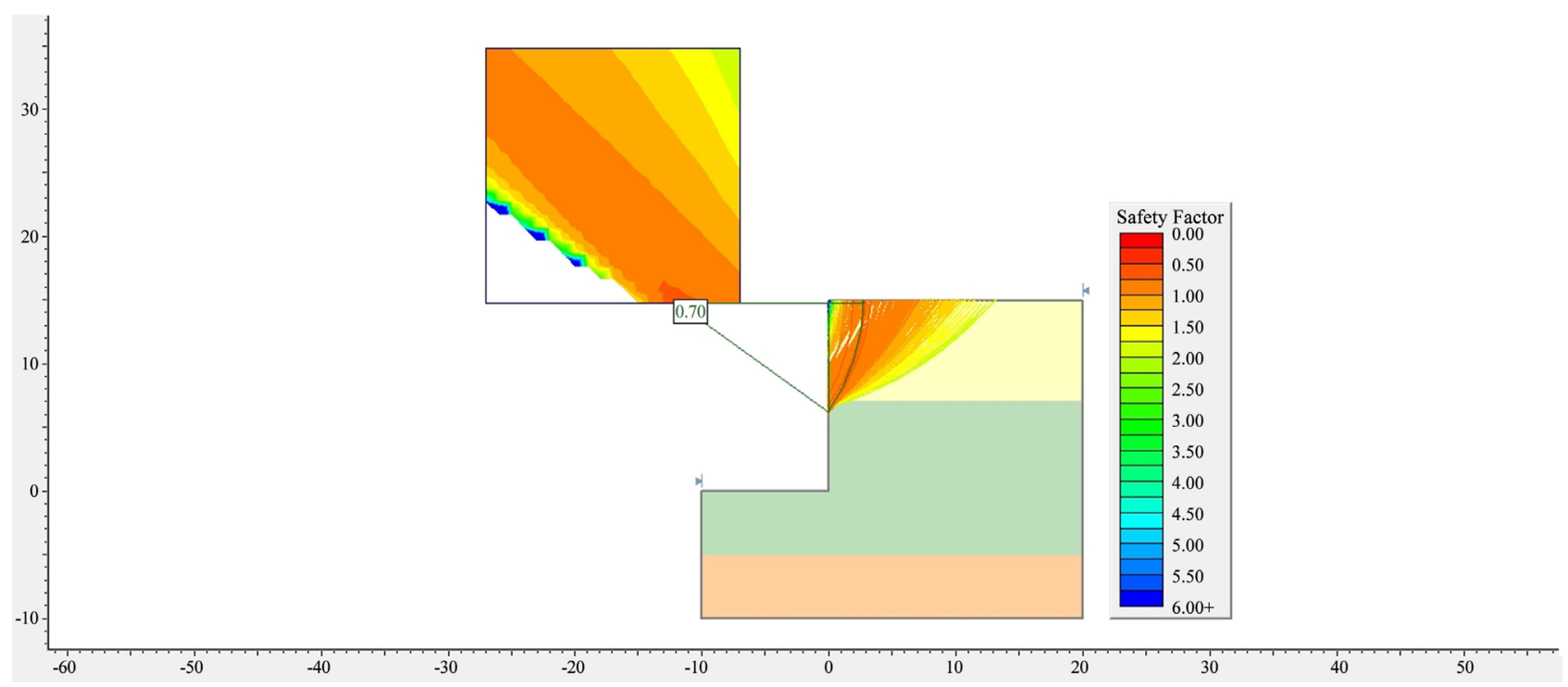

Figure 8. Analsis with SLIDE software in the normal states at depths of 15 meters (Niavaran hole).

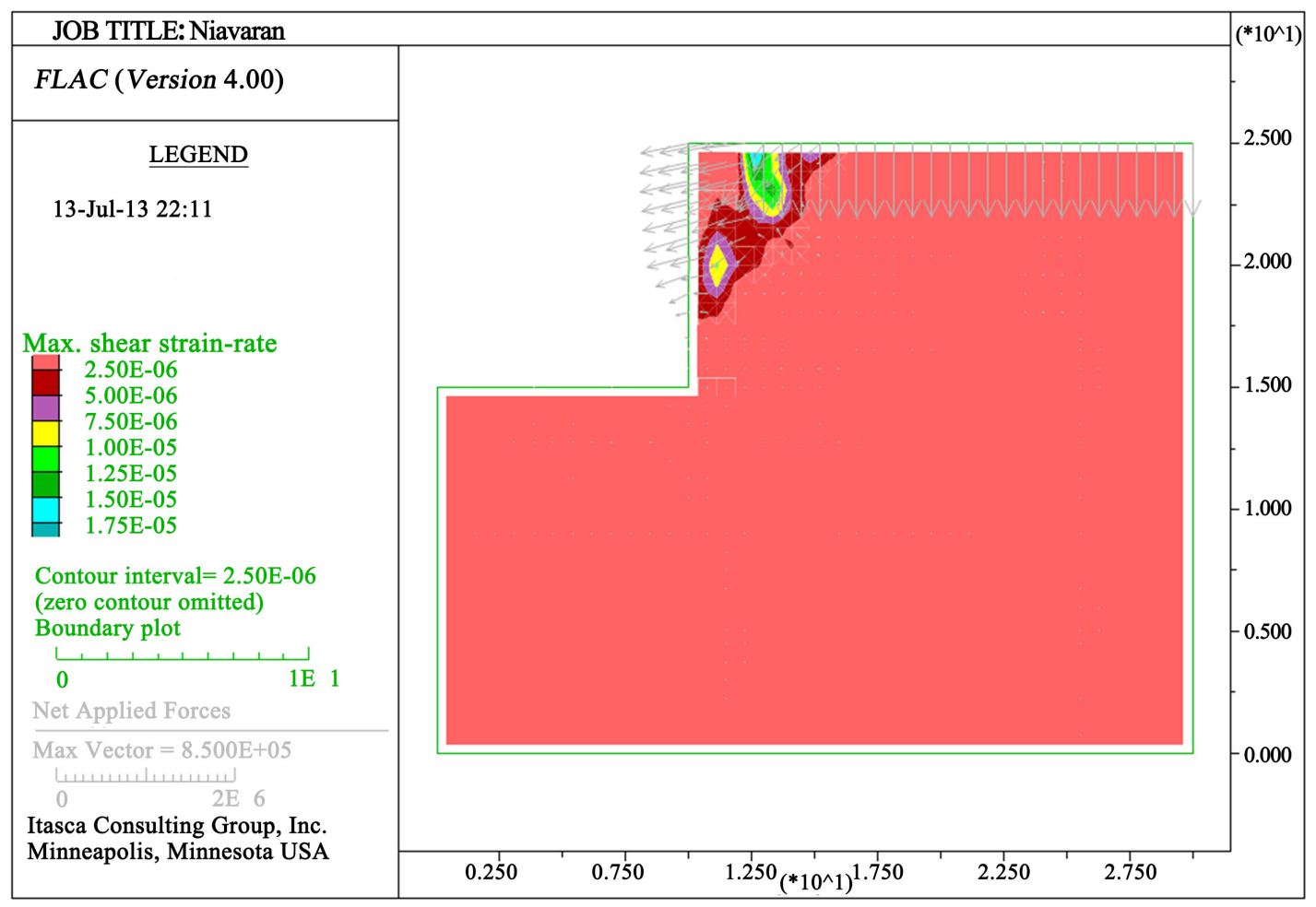

Figure 9. Analysis with FLAC software in the with load states at depths of 10 meters at distance of 3 meters (Niavaran hole).

Table 1. Confidence coefficients obtained at different excavation depths using numerical and partial equilibrium methods for Amir Kabir hole.

\begin{tabular}{|c|c|c|c|c|}
\hline & & Analysis with FLAC & & Analysis with SLIDE \\
\hline$(\mathrm{m})$ & $\begin{array}{l}\text { Confidence } \\
\text { coefficients in } \\
\text { normal mode }\end{array}$ & $\begin{array}{c}\text { Confidence } \\
\text { coefficients with load } \\
\text { in } 3 \text { meter }\end{array}$ & $\begin{array}{l}\text { Confidence } \\
\text { coefficients in } \\
\text { normal mode }\end{array}$ & $\begin{array}{l}\text { Confidence coefficients } \\
\text { with load in } 3 \text { meter }\end{array}$ \\
\hline
\end{tabular}




\begin{tabular}{ccccc} 
Continued & & & & \\
\hline 1 & 1.93 & 0.73 & 1.50 & 1.50 \\
2 & 1.22 & 0.55 & 1.01 & 1 \\
3 & 0.93 & 0.46 & 0.83 & 0.83 \\
4 & 0.74 & 0.37 & 0.75 & 0.75 \\
5 & 0.64 & 0.33 & 0.72 & 0.72 \\
6 & 0.57 & 0.30 & 0.67 & 0.67 \\
7 & 0.51 & 0.25 & 0.65 & 0.65 \\
8 & 0.46 & 0.22 & 0.62 & 0.62 \\
9 & 0.41 & 0.17 & 0.58 & 0.58 \\
10 & 0.38 & 0.14 & 0.56 & 0.56
\end{tabular}

In Figure 10 a sample of analyzes performed by the SLIDE software is shown for the case where the load is located at a distance of 3 meters from the edge of the hole and a depth of hole is 9 meters.

The results of the analyzes performed for Niavaran hole in the normal state and the existence of the neighboring building load are shown in Table 2 that the red values represent the critical depth of the excavation. Their diagrams in the form of changes in the confidence coefficient versus depth of excavation for each numerical method and partial balance are shown in Figure 11 as the depth of excavation increases the confidence coefficient follows a downward trend.

\subsection{The Effect of Fault in Determining the Critical Depth of Excavation in Niavaran Hole Alluvial}

This hole is located on the Niavaran fault which can be used to detect this fault in the $\mathrm{TP}_{3}$ to $\mathrm{TP} 8$ section in Figure 12.

In the cross-section we are seeing the displacement of coarse-grained soil without gravel which contains rubble.

Due to manual drill boreholes the upper depths mainly consist of layers of sand and gravel which turns into coarse soil. After 12 meters deep rubble was added to the coarse soil (Figure 13).

\section{Discussion and Conclusion}

Amir Kabir hole is located on the $\mathrm{C}$ alluvial of Tehran and numerical results show that in the absence of neighboring building load the depth of excavation is in the range of 1 to 1.5 meters, and also the results of the extreme equilibrium method in this case indicate that the depth of the stable hole is in the range of 1 meter.

When the load is placed at a distance of 3 meters from the edge of the hole, the results of the numerical method indicate that there is no possibility of stable excavation and the reason is that in the FLAC software in this situation there follows the emergence of a local instability problem and the software cannot 
solve the total force for the entire system. As a result the resulting confidence coefficient is related to the soil under the load from the building not the edge of the hole.

Table 2. Confidence coefficient obtained at different excavation depth using numerical and partial equilibrim methods for Niavaran hole. According to this charts, they show changes in the reliability coefficient versus depth of excavation for each numerical and partial equilibrium method in Figure 11. By increasing the depth of excavation, the confidence coefficient follows a downward trend.

\begin{tabular}{|c|c|c|c|c|}
\hline & & & $\begin{array}{c}\text { Analysis with } \\
\text { FLAC }\end{array}$ & Analysis with Slide \\
\hline Depth (m) & $\begin{array}{l}\text { Confidence } \\
\text { coefficients in } \\
\text { normal mode }\end{array}$ & $\begin{array}{c}\text { Confidence } \\
\text { coefficients with } \\
\text { load ( } 5 \text { storey } \\
\text { building) at a } \\
\text { distance of } 3 \text { meters } \\
\text { from the hole edge }\end{array}$ & $\begin{array}{l}\text { Confidence } \\
\text { coefficients in } \\
\text { normal mode }\end{array}$ & $\begin{array}{c}\text { Confidence } \\
\text { coefficients with } \\
\text { load ( } 5 \text { storey } \\
\text { building) at a distance } \\
\text { of } 3 \text { meters from the } \\
\text { hole edge }\end{array}$ \\
\hline 1 & 4.21 & 0.87 & 3.33 & 3.31 \\
\hline 2 & 2.18 & 0.70 & 1.89 & 1.88 \\
\hline 3 & 1.52 & 0.58 & 1.42 & 1.42 \\
\hline 4 & 1.22 & 0.50 & 1.2 & 1.2 \\
\hline 5 & 1.04 & 0.46 & 1.09 & 1.09 \\
\hline 6 & 0.91 & 0.42 & 1.04 & 1.04 \\
\hline 7 & 0.82 & 0.38 & 0.99 & 0.99 \\
\hline 8 & 0.75 & 0.34 & 0.95 & 0.94 \\
\hline 9 & 0.67 & 0.30 & 0.90 & 0.90 \\
\hline 10 & 0.61 & 0.28 & 0.86 & 0.86 \\
\hline
\end{tabular}

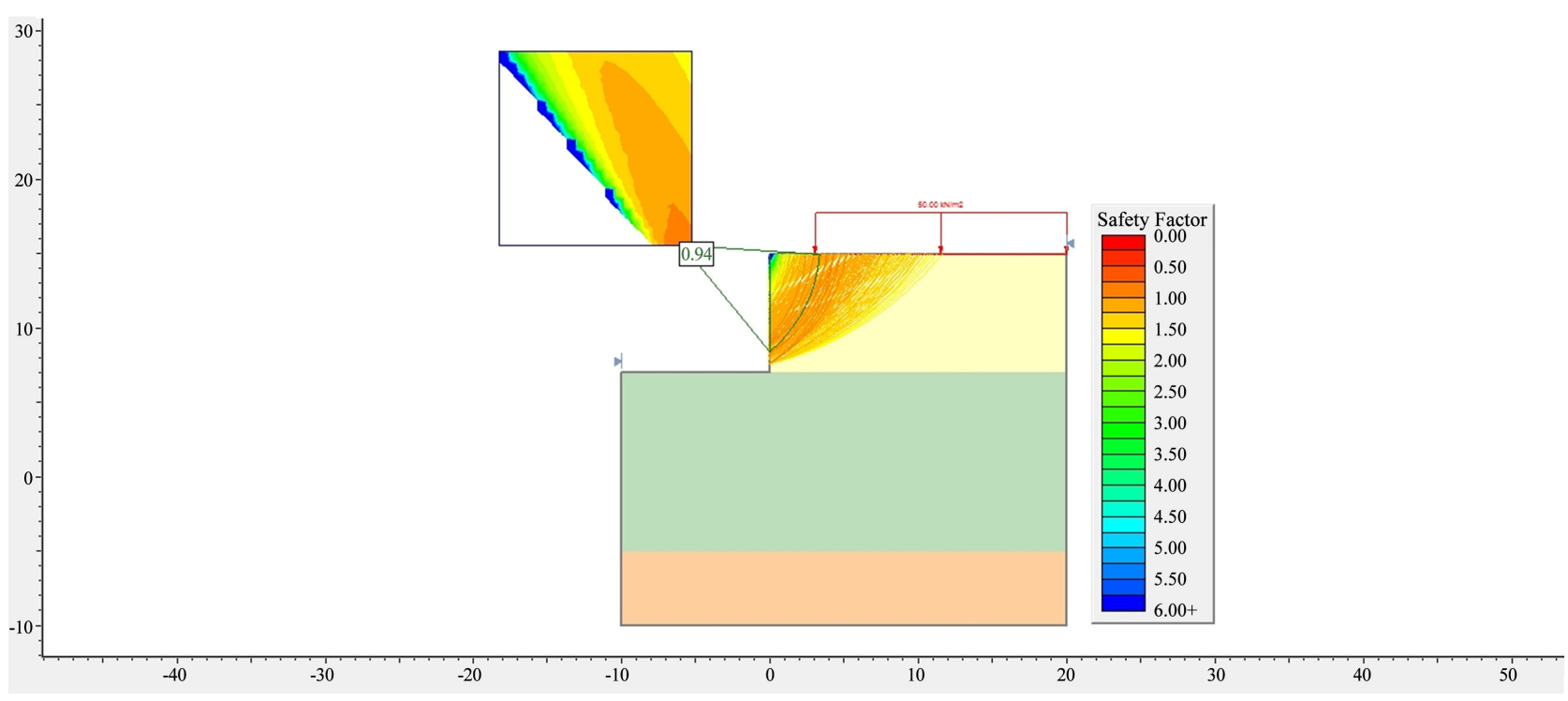

Figure 10. Analsis with SLIDE software in the with load states at depths of 8 meters at distance of 3 meters (Niavaran hole). 


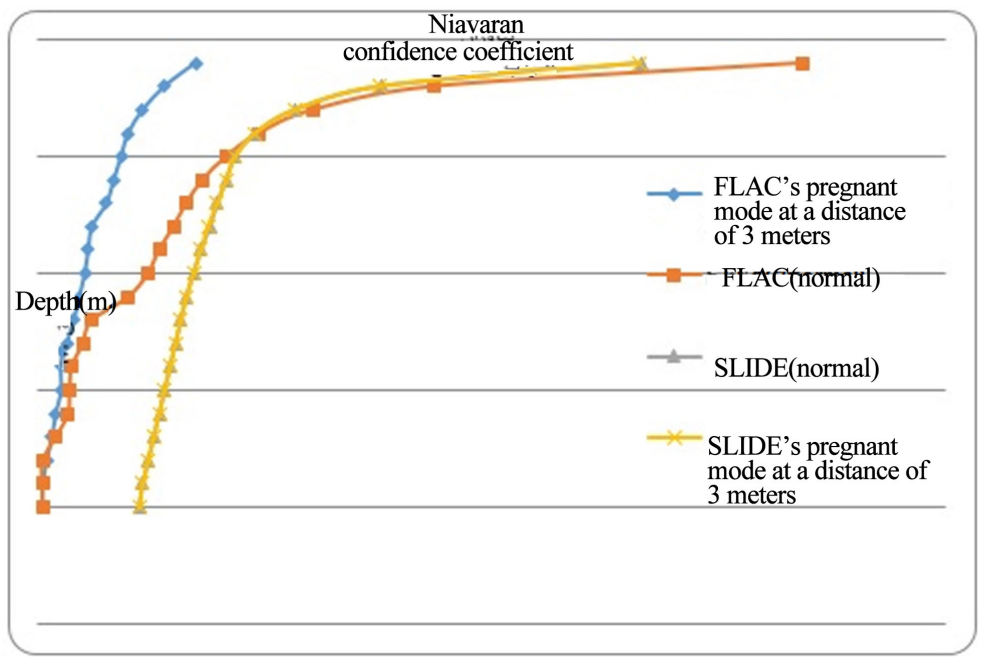

Figure 11. Depth confidence coefficient change for both SLIDE and FLAC software for normal and pregnant mode (Niavaran hole).

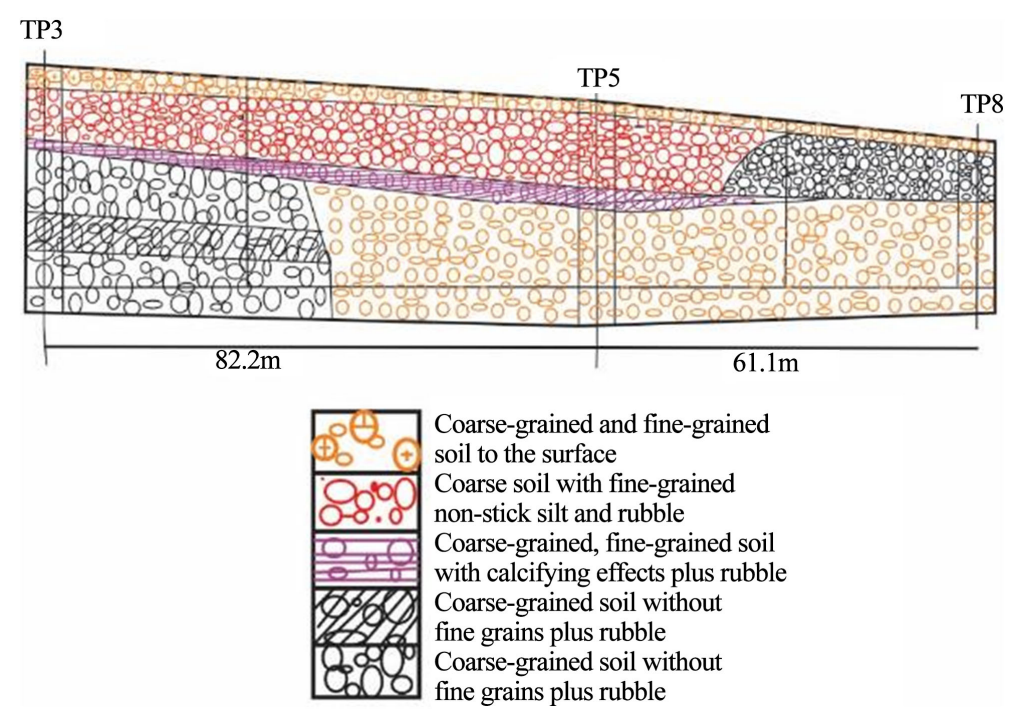

Figure 12. Cross section of Niavaran hole from TP2 to TP8. Due to the fault of Niavaran, there is a level of displacement [4].

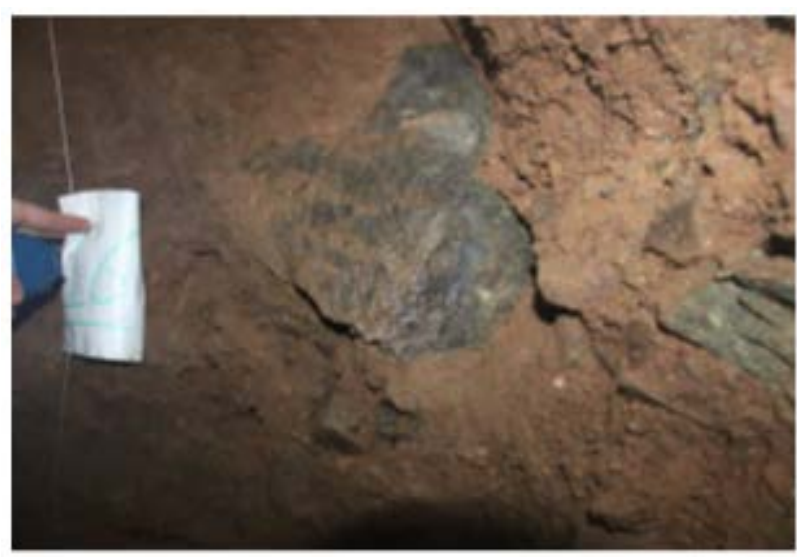

Figure 13. Rock fragments at a depth of 16 meters in the TP7 borehole. 
However, the results of the equilibrium method indicate that when the load is located at a distance of 3 meters from the edge of the hole, the depth of the Sustainable hole is up to 1 meter and the difference is very low. Of course it should be noted that SLIDE software does not have much effect on its instability when the load will fall outside the slipping area, and as it is seen in the corresponding figure on the output of the SLIDE software when the load is located at a distance of 3 meters from the edge of the hole. The load arrived to the building to a small percentage of the slip area and cannot correctly reflect the impact of the load on the instability of the hole. Of course this does not mean that the results of the equilibrium method cannot be used to investigate the effect of the load on the instability of the hole but it means that up to a depth of one meter can be excavated without the guardian structure, but on the side building foundation due to the poor geotechnical characteristics of the project site soil We will have a deformation not a possible fall.

For deep excavations in this area, when the load is located at a distance of 3 meters from the edge of the hole with the SLIDE software the length of the guard structure is 16 meters and is placed at a slope of 15 degrees on the hole and the mechanical characteristics are as follows:

\section{Support Properties}

Support: Support 1

Support 1

Support Type: End Anchored;

Force Application: Active;

Out-of-Plane Spacing: $0.9 \mathrm{~m}$;

Anchor Capacity: $80 \mathrm{kN}$.

A sample of analyzes conducted with the encouraging guard structure constructed by the SLIDE software is shown in Figure 14.

In order to verify the results obtained from the analysis carried out in this hole a field observation was done. In the visits there was little difference between the results and the constant depth of the hole in reality. Figure 15 refers to a hole in the collapse of Tajrish, and the characteristics of its engineering geology are similar to those of the geological hole and as seen in the hole shown. The hole has remained steady in the presence of the neighboring building load to a depth of 1 $\mathrm{m}$ without the guard structure (The point of this figure is that at a distance of one meter of the edges of the lateral structure are stable).

The Niavaran hole is located on Tehran's $\mathrm{C}$ alluvial and the results of numerical methods show that in the absence of neighboring building load the depth of excavation is 3 meters in length and also the results of the partial equilibrium method in this case indicate that the depth of the steady hole is in the range of 2 to 2.5 meters. When the load is placed at a distance of 3 meters from the edge of the hole, the results of the numerical method indicate that there is no possibility of stable excavation and the reason is that in FLAC software in this situation follows the emergence of topical instability and the software cannot solve the 
input force for the whole system. As a result the confidence coefficient is related to the soil under load from the building not the edge of the hole. However the results of the equilibrium method indicate that when the load is located at a distance of 3 meters from the edge of the hole, the depth of the stable hole is 2 to 2.5 meters, and up to 6 meters it is stable critically and the difference is very low. Of course it's worth mentioning in SLIDE software when the load is outside the sliding area it will not have much effect on its instability, and as seen in the corresponding figure on the output of the SLIDE software when the load is located at a distance of 3 meters from the edge of the hole the load arrived from the building to a small percentage of the slip area and cannot correctly reflect the impact of the load on the instability of the hole. Certainly, this does not mean that the results of the equilibrium method cannot be used to investigate the effect of the load on the instability of the hole but it means that up to a depth of 2 to 2.5 meters can be excavated without a guardian structure, but on the side building foundation due to the poor geotechnical characteristics of the project site soil We will have a deformation not a possible fall. For deep excavations in this area, when the load is located at a distance of 3 meters from the edge of the hole with the SLIDE software the length of the guard structure is 16 meters and is placed at a slope of 15 degrees on the hole and the mechanical characteristics are as follows:

\section{Support Properties}

Support: Support 1

Support 1

Support Type: End Anchored;

Force Application: Active;

Out-of-Plane Spacing: $1 \mathrm{~m}$;

Anchor Capacity: $70 \mathrm{kN}$.

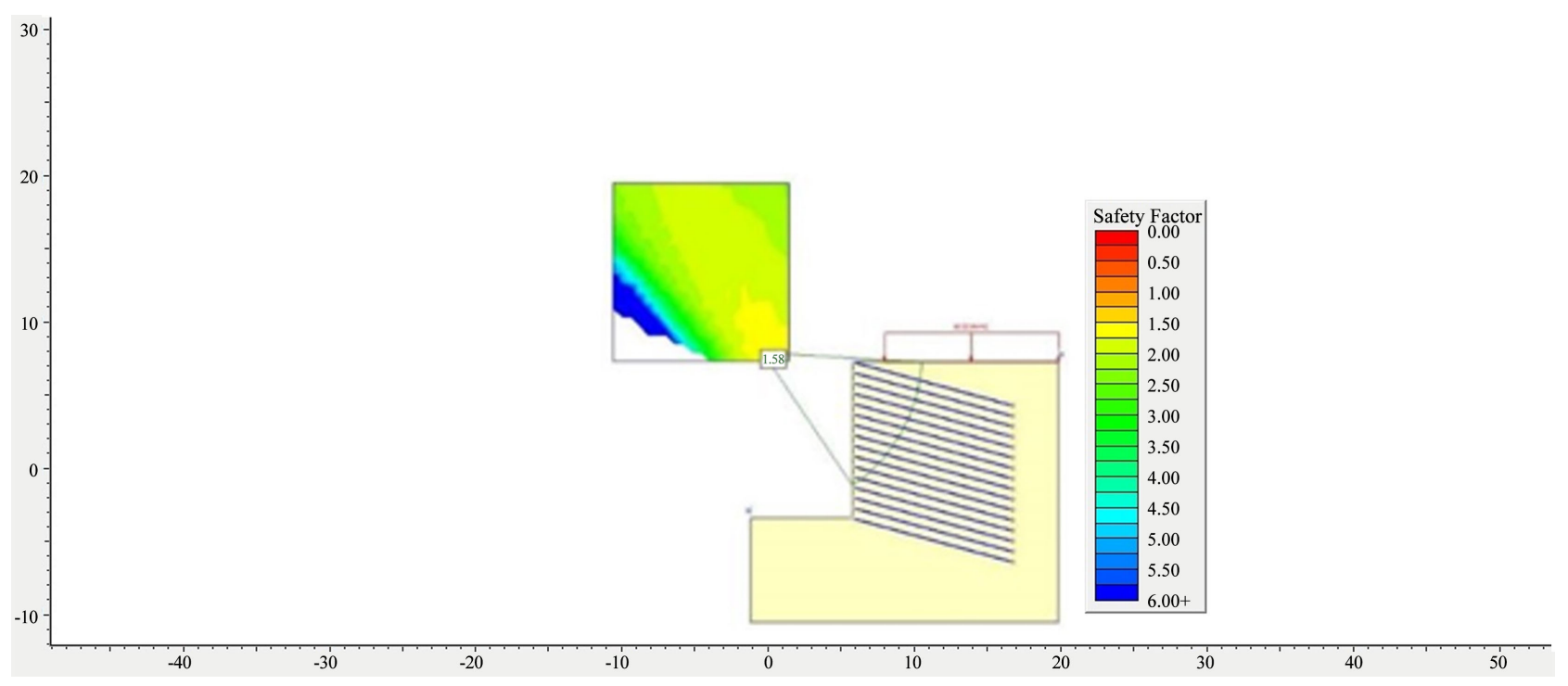

Figure 14. SLIDE Software Output For a condition where the load is located at a distance of 3 meters from the edge of the hole and using the guard structure of the encouraging the depth of the hole is $15 \mathrm{~m}$. 
A sample of analyzes conducted with the guardian structure of the encouraging performed by the SLIDE software is shown in Figure 16.

In the end for the verification the results of field surveys have been done.

In the observations, there has been little difference between the results and the depth of the stable hole in reality. Figure 17 is related to the southwest of the Niavaran hole which will remain steady to a depth of 3 meters without a guardian structure in the without load state of the neighboring building, and to a depth of 6 meters will be steady critically.

By analyzing two extreme equilibrium methods using slide software and numerical method using FLAC software we obtained confidence coefficients in each meter of the holes that Based on the type of alluvial Table 3 can be plotted. Due to the geologic characteristics of the Niavaran hole, which is located on the fault, faulting in this hole has caused a crushed zone to be created and finally the cementation of this section of $\mathrm{C}$ alluvial is more than the other sections and The critical depth of excavation in this part of the alluvial is higher than other sections.

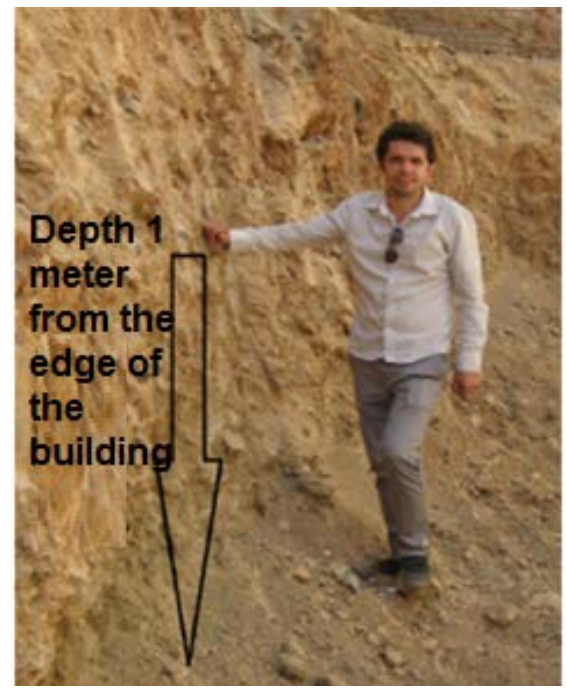

Figure 15. The hole located near the Tajriysh with a depth of 3 meters (summer 1392) Niavaran hole.

Table 3. Critical depth of excavation in area with faults and without faults.

\begin{tabular}{|c|c|c|c|c|c|c|}
\hline \multicolumn{4}{|c|}{ Critical excavation depth in meters } & \multicolumn{2}{|c|}{ Alluvial Type } & \multirow{3}{*}{$\begin{array}{c}\text { The name of } \\
\text { the hole }\end{array}$} \\
\hline $\begin{array}{l}\text { Existence of a 5-storey buildi } \\
\text { distance of } 3 \text { meters from the ec }\end{array}$ & $\begin{array}{l}\text { ad at a } \\
\text { the hole }\end{array}$ & \multicolumn{2}{|c|}{ Mode of neighboring load } & \multirow{2}{*}{$\begin{array}{l}\text { In terms of } \\
\text { the table }\end{array}$} & \multirow{2}{*}{$\begin{array}{l}\text { In terms } \\
\text { of map }\end{array}$} & \\
\hline $\begin{array}{l}\text { Encouraging characteristics with a } \\
\text { confidence coefficient of } 1.5\end{array}$ & $\begin{array}{c}\text { Partial } \\
\text { Equilibrium }\end{array}$ & $\begin{array}{l}\text { Numerical } \\
\text { equilibrium }\end{array}$ & $\begin{array}{c}\text { Partial } \\
\text { Equilibrium }\end{array}$ & & & \\
\hline $\begin{array}{l}\text { Length } 16 \mathrm{~m} \text {, slope } 15^{\circ} \text {, tensile } \\
\text { strength } 80 \mathrm{kN} \text {, distance } 1 \mathrm{~m}\end{array}$ & 6 & 5 & 6 & $\mathrm{C}$ & $\mathrm{C}$ & $\begin{array}{l}\text { Niavaran } \\
\text { (fault) }\end{array}$ \\
\hline $\begin{array}{l}\text { Length } 16 \mathrm{~m} \text {, slope } 15^{\circ} \text {, tensile } \\
\text { strength } 80 \mathrm{kN} \text {, distance } 0.9 \mathrm{~m}\end{array}$ & 2 & $2 / 5$ & 2 & $\mathrm{C}$ & $\mathrm{C}$ & $\begin{array}{l}\text { Amir } \\
\text { Kabir }\end{array}$ \\
\hline
\end{tabular}




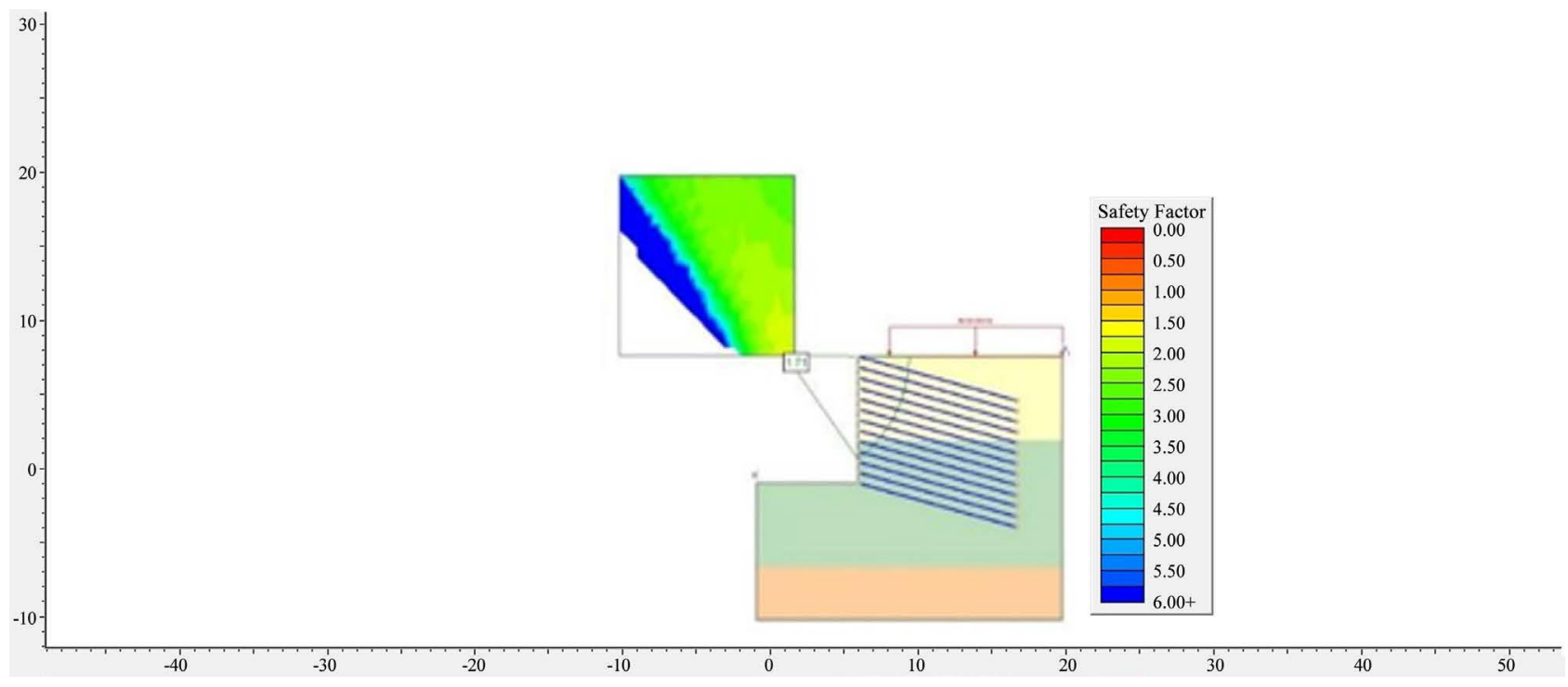

Figure 16. SLIDE software output for a condition where the load is located at a distance of 3 meters from the edge of the hole and using the guard structure of the encouraging the depths of the hole is $12 \mathrm{~m}$.

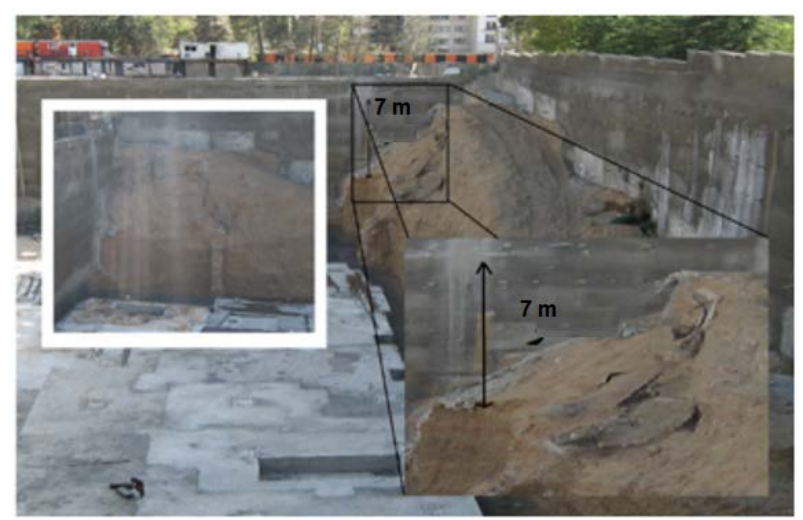

Figure 17. The Southwest of the Niavaran hole that has fallen.

\section{Acknowledgements}

We thank the observers and organizations who helped us in the article. We thank Shams omran consulting engineers institute and Eslamic Azad University.

\section{Conflicts of Interest}

The authors declare no conflicts of interest regarding the publication of this paper.

\section{References}

[1] Cheshomi, A., et al. (2006) Study of Mechanical Properties of Coarse Alluvial in Tehran Based on Usual Tests and Simple Mechanical Tool. PhD Thesis, Tarbiat Modarres University, Tehran.

[2] Jafari, M., et al. (2002) North Seismic Zone Report from the Point of View of the Site. International Institute of Seismology and Earthquake Engineering, National Council for Scientific Research. 
[3] Tahooni, S. (2006) Geotechnical Engineering: Principles \& Practices. 2nd Edition, Pearson, London.

[4] Shams Omran Consulting Engineers (2011) Geo-Technical Studies Report of Niavaran Project. 